\title{
THE METHOD TO OBTAIN POSITION USING GNSS AND RFID FOR REALIZATION OF INDOOR AND OUTDOOR SEAMLESS POSITIONING
}

\author{
${ }^{a}$ Masaaki Shikada, ${ }^{a}$ Soichiro Shiraishi and ${ }^{b}$ Sayaka Takeuchi \\ Dept. of Environment and Civil Engineering, Kanazawa Institute of Technology, 7-1 Ohgigaoka, Nonoichi, Ishikawa, Japan \\ ${ }^{b}$ PASCO CORPORATION 1-1-2 Higashiyama, Meguro-ku, Tokyo 153-0043, Japan \\ shikada@neptune.kanazawa-it.ac.jp
}

Commission IV ,WG IV/1

KEY WORDS: Satellite, Accuracy, GIS, Measurement, Spatial Infrastructures

\begin{abstract}
:
To obtain indoor positioning by using GPS (GNSS) satellite is difficult now. Additionally it is difficult to obtain high accuracy outdoor position when GPS receiver cannot find four or more GPS satellites in the viewing field of sky. The Japanese Government executed a new law NSDI (National Spatial Data Infrastructure) for a spatial information society on May 30, 2007. In this law, everybody can know positional information in real time, anytime and anywhere. In addition, it is necessary to use satellite positioning for realization of seamless positioning, and to promote ubiquitous network technology. Realization of advanced geospatial information society will achieve by creating condition which can obtain positional information anytime and anywhere. However, those technologies have not been established yet. Our laboratory conducted seamless positioning experiment to verify whether it can obtain position seamlessly by using VRS-GPS (Virtual Reference System-GPS),QZSS(LEX signal) and RFID (Radio Frequency Identification) for realizing an advanced spatial information society. Especially, QZSS was launched in 2010 by JAXA and is satellite system taken by a combination of multi orbit plane and each satellite deployed to appear constantly 1 satellite near the zenith in Japan. We are joining the demonstration experiment of a part of Hokuriku area in Japan at 5th to 9th in March and 23th to 27th in April 2012. In this paper we described advanced spatial information society will realize by a combination of GPS(GNSS),RFID and QZSS.
\end{abstract}

\section{INTROIDUCTION}

Japan is now experiencing an aging society and every a person should be safe and feel relieved. The Japanese Government executed a new law for a spatial information society on May 30, 2007. In this law, everybody can know positional information in real time anytime and anywhere, both of the mappings of a national common base map, and environment for utilizing satellite systems. In addition, it is necessary to keep satellite positioning for realization of seamless positioning, and to promote ubiquitous network technology.

Method of obtaining position has been mainly using GNSS by surveyor and researcher now. Most Japanese surveyor and researcher have been obtaining the position by using GPS which created by the USA. We can obtain high accuracy position by using GPS in open sky, however, position in closed sky cannot obtain accurate position which was caused by multipath and cycle slip.

In additionally, it is necessary to obtain detailed indoor position because many people are also acting in indoor such as underground mall in recent years; however, the technologies have not been established yet. To ensure life of safety, relief and comfort for many people, method of obtaining indoor position should be early established and innovate in the field of geoinfomatics. Other researchers have tried to obtain indoor position by using communication device such as Bluetooth, ultra wideband radio and Wi-Fi (Wireless Fidelity), but it has not developed to a practical level yet.

We focused RFID to obtain indoor position. RFID has already been used in the field of commerce and it is used for electronic money services in country ICT.

On the other hand "The map should be fresh" is a concept of our laboratory. REAL TIME GIS is the system for real-time mapping at the field site using Real-Time Kinematic - GPS (RTK-GPS) and GIS as shown on the Figure 1. It is possible to update Digital Map data in real time by using a cellular phone and RTK-GPS which has simultaneity. Concept of "Real Time GIS" has been studied for about a decade by us. This system has already been completed but it does not supported to obtain indoor positioning because it was developed to obtain outdoor positioning. Latest indoor and outdoor position using GNSS, RFID and another system must immediately need to update on GIS. When we will get latest and accurate position anytime and anywhere at real time, everyone can live safely.

The purpose of our laboratory is to conduct verification experiment to verify whether RFID can obtain indoor position as a method of complementing indoor position to promote for realizing an advanced spatial information society by enactment of NSDI. Furthermore REAL TIME GIS is to add system which updated indoor position in real time.

Verification experiment is to perform seamless positioning by using passive RFID in the area where GPS signals could not be received to obtain information of absolute positions. And an experiment was performed based on the assumption that user will obtain the position information in an inside of the building by using active RFID.

\section{KIND OF RFID}

RFID is available passive and active types. The passive type performs communicate by receiving radio waves in from an antenna device and sending back information. It can be miniaturized and thinned easily, and it can be produced at a low 


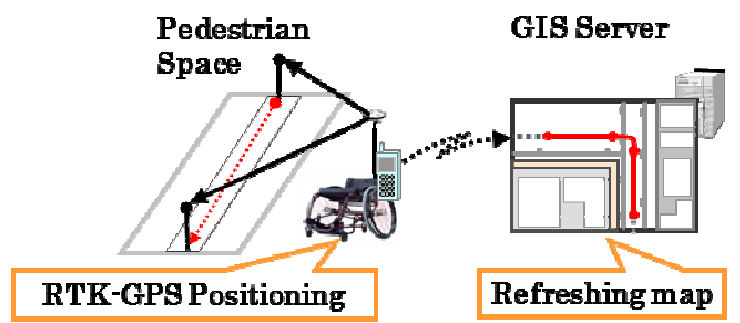

Figure 1. Concept of "Real Time GIS"

price. The active type can perform communication by automatically transmitting be RFID's reader, and it is embedded with a battery. It has an advantage of achieving a longer radio waved than the passive type although the battery needs to be changed.

\section{VERIFICATION EXPERIMENT FOR SEAMLESS POSITIONING BY PASSIVE RFID}

To realize an advanced spatial information society, it should need to obtain positioning information anywhere and seamless positioning is indispensable for realization advanced geospatial information society. We conducted seamless positioning to verify whether it can obtain seamless positioning between GPS and RFID on the GIS. GPS was measured in open sky, and RFID tags can complement that GPS receiver could not receive signals from GPS satellites at an area surrounded by canopies and buildings. An experiment was performed inside the KIT campus at Kanazawa district in central Japan. KIT campus has both of open sky and close sky. On the experiment RFID has to write position information into the tag in advance. Therefore, to obtain position information put in tag, we did static positioning by GPS at two positions which include open sky and canopies. Coordinate which entered tags were obtained by interpolated. Installation intervals of tags are $1.2 \mathrm{~m}$ because human's walking speed is about $4 \mathrm{~km} / \mathrm{h}$ and GPS data obtains coordinate 1 point at 1 second. Structural elements of experimental machine which include GPS receiver and RFID reader attached to wheelchair are shown in Figure 2. We walked with wheelchair and measured position information around in campus.

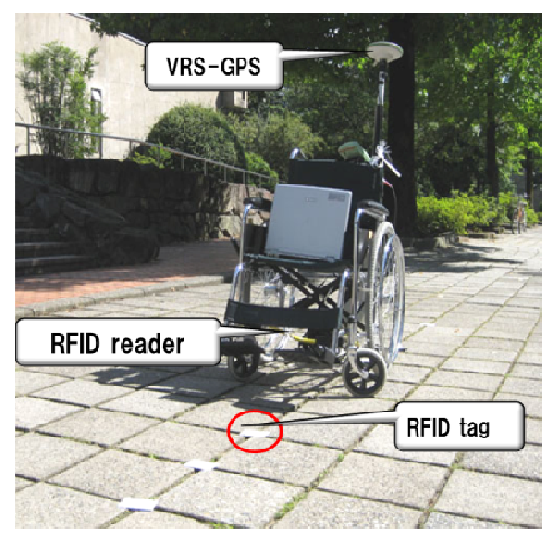

Figure 2. The equipment by experiment

\subsection{Equipment}

The equipment used is made of Welcat Inc. and specification details are below.

- RFID's reader: EFG-400-01

- An antenna of exclusive RFID's reader writer: ANU-100-01
- RFID tag: card type (ISO15693, 13.56MHz)

\subsection{Results and experimental considerations}

Figure 3 shows that position of VRS-GPS and passive RFID were overlapped on the aerial photographic map by GIS. Background is air photograph of Kanazawa Institute of technology taken by aircraft. Circle of black and white shows the track obtained by VRS-GPS and passive RFID respectively. It was confirmed locations where GPS receiver did not receive could complement positioning information by passive RFID. Figure 2 indicated that border position can connect seamlessly. It is difficult to obtain a high accuracy positioning around buildings, because large errors arise by cycle slip and multi-path. These effects may avoid by RFID. Positional information were able to obtain seamlessly, however, the experiments had the problem that overlapped track of both is too long as shown in Figure 4.

It is difficult to find position to set the first passive RFID. The number of tag should be decrease to use this principle in a social experiment. Therefore, it was necessary to investigate method to minimize the number of RFID for time and labor. The solution of the problem is to use QZSS (Quasi-Zenith Satellites System). QZSS was launched in 2010 by JAXA and is satellite system taken by a combination of multi orbit plane and each satellite deployed to appear constantly 1 satellite near the zenith in Japan. It is expected to obtain high accuracy position information around the building. Thus, this problem may solve by QZSS.

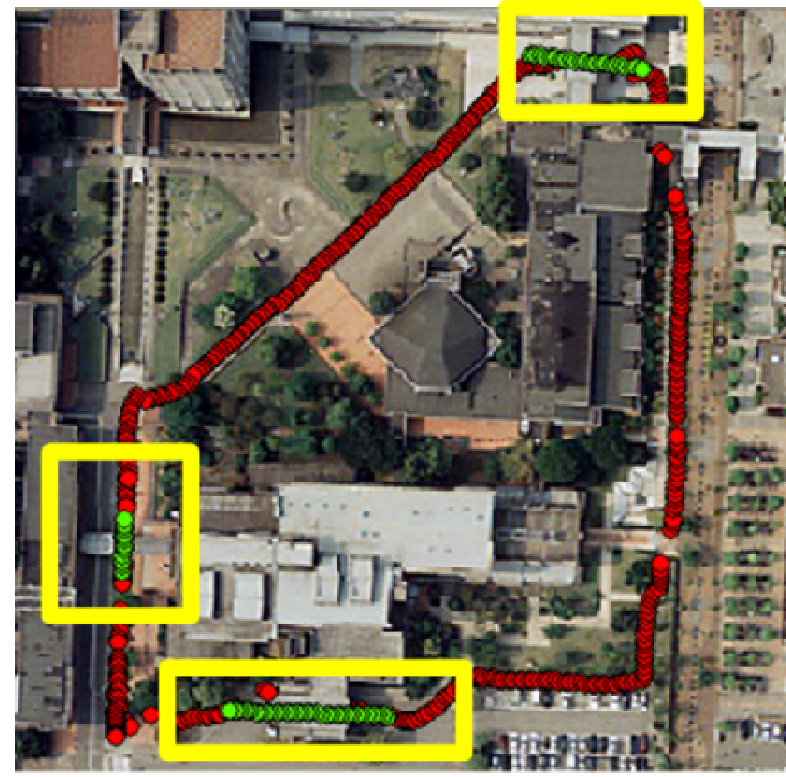

Figure 3. Overlapping display of experimental data

\subsection{Experimental outline using QZS}

GPS could not obtain high accuracy position anytime, however QZS will measure as a powerful tool at outdoor area. Accuracy verification experiment was supposed to conduct using LEX signal of QZS that has promising accuracy as a level of centimeter, however it was postponed until spring of 2012 because creation of offset information had difficulty by crustal deformation of GPS-based control station from the effect of "The 2011 off the Pacific coast of Tohoku Earthquake" which occurred on March 11, 2011. In this paper describes outline of verification experiment. 


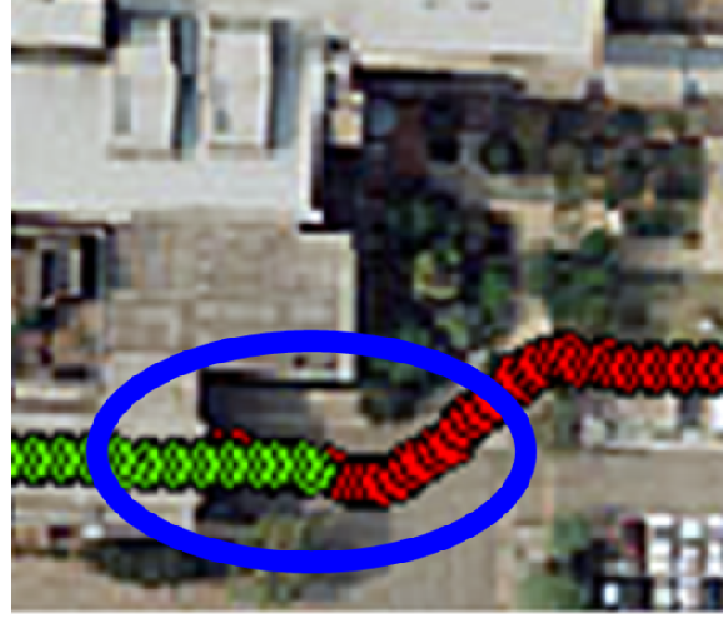

Figure 4. Overlapped track of GPS and RFID

\subsubsection{Accuracy verification at known reference point}

Accuracy verification experiment will be conducted to measure position at known reference point. VRS-GPS receiver and LEX signal receiver set up on control point are measured by static positioning for 3 minutes. This experiment is conducted on two patterns that QZS located at the zenith and out of zenith in the morning and afternoon respectively. We verify gaps of control point by measuring using each receiver.

\subsubsection{Accuracy verification at temporal control point}

Accuracy verification experiment will be conducted to measure position of temporal control point by VRS-GPS, LEX signal and Total Station. Temporal control point is set up in separate position of open sky $10 \mathrm{~m}$ from known reference point. On the other hand, it set up around the building and the tree. Accuracy verification is conducted by affecting multipath and cycle slip.

\subsubsection{Accuracy verification by moving speed}

Accuracy verification by moving speed is conducted by attaching LEX signal receiver on motor vehicle. Moving speed will be within a range of 4 to $60 \mathrm{~km} / \mathrm{h}$ and positioning device is fitted LEX signal receiver, VRS-GPS and D-GPS. An experiment is verified by each moving speed that can receive LEX signal and difference of Time To First Fix by each GNSS.

\section{VERIFICATION EXPERIMENT FOR SEAMLESS POSITIONING BY ACTIVE RFID}

\subsection{Limited receiving range of reader}

It exists the limit range where tag can be received normally the signal though active RFID has the advantage with long communication distance. As shown in Figure 5, the experimenter with the tag walked toward a reader from a distance position. We investigated whether the reader could be read a tag at any position. However the shielding material was not set between a reader and a tag in the experiment condition.

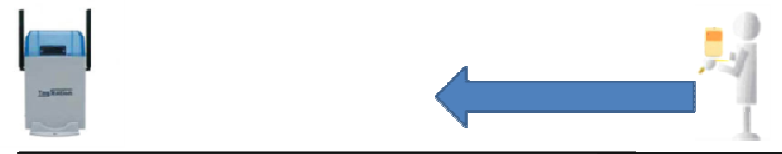

Figure 5. Experimenter with the tag walked toward a reader from distance position

\subsection{Equipment}

Equipment was made by KYUSYU TEN Co., Ltd.

【Hardware 】

- Product name: TagStation

- Wi-Fi model faint wireless reader

- Faint wireless writer

- Faint wireless tag

- Wireless Router

【Software 】

Made by I-O DATA DEVICE .INC.)

- Product name: TagStation

- Location management system

- Setting reader program

- $\quad$ Setting tag program

Microsoft SQL Server 2005 Express Edition

\subsection{Results and considerations}

Table 1 shows distance that the reader read position of the farthest tag. This experiment was repeated 7 times and the distance average is $12 \mathrm{~m}$.As a results, maximum reader range is $12 \mathrm{~m}$. Thus, setting intervals of reader is advisable to set radius $12 \mathrm{~m}$ intervals in using many readers at wide area.

\begin{tabular}{|c|l|l|l|l|l|l|l|}
\hline Times & 1 & 2 & 3 & 4 & 5 & 6 & 7 \\
\hline $\begin{array}{l}\text { Walking } \\
\text { speed } \\
{[\mathrm{m} / \mathrm{s}]}\end{array}$ & 1.20 & 1.25 & 1.20 & 1.20 & 1.20 & 1.25 & 1.15 \\
\hline $\begin{array}{l}\text { Distance } \\
{[\mathrm{m}]}\end{array}$ & 10 & 14 & 11 & 11 & 14 & 14 & 10 \\
\hline
\end{tabular}

Table 1. Distance that the reader read position of the farthest tag

\subsection{Relationship between RSSI, ATT and distance}

Active RFID can confirm value of RSSI and ATT by recording data of viewer. RSSI means a sensitivity of tag receiver, and it changes from interval of receiver distance. ATT is attenuator and signal of it is classified into 3 types which are high, medium and naught. An experiment was conducted to verify whether RSSI indicates concrete interval. ATT values of RSSI were investigated when the examinee moves away from reader every $50 \mathrm{~cm}$ (Figure 6).

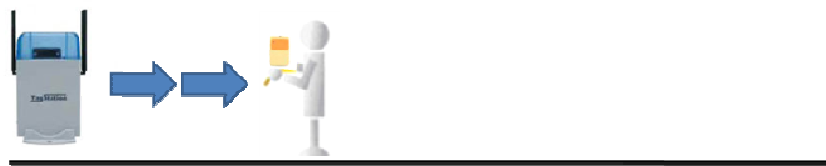

Figure 6. Experimental outline of RSSI and ATT

\subsection{Results and considerations}

Table 2 shows the relationship between RSSI and ATT as maximum range with high, medium and naught of ATT. RSSI by each level of ATT were almost no change regardless of received range. Maximum received range $12.5 \mathrm{~m}$ and farther range could not receive information of tag. The change of range by ATT and specific range by RSSI could not confirm in the experiment. However, receiving range of RSSI will be able to roughly estimate position of tag. 


\begin{tabular}{|r||c|c|c|c|}
\hline \multicolumn{1}{|c||}{ RSSI } & \multicolumn{3}{c|}{ ATT } & received \\
\cline { 2 - 5 } & high & medium & naught & [m] \\
\cline { 2 - 5 } & \multicolumn{3}{|c|}{ Received range[m] } & 0.0 \\
\hline \hline 10 & & - & 0.0 & 1.0 \\
\hline 9 & $0.5 \sim 1.0$ & - & 1.0 & 5.5 \\
\hline 8 & $0.0 \sim 5.5$ & $0.0-4.5$ & $0.5 \sim 5.5$ & 6.5 \\
\hline 7 & $2.0 \sim 6.0$ & - & $2.5 \sim 6.5$ & 8.0 \\
\hline 6 & 8.0 & $5.0-8.0$ & $6.0 \sim 7.5$ & 8.5 \\
\hline 5 & 6.5 & 6.5 & $8.0 \sim 8.5$ & 11.5 \\
\hline 4 & $7.0 \sim 11.5$ & $7.0 \sim 11.0$ & $7.0 \sim 11.0$ & 12.5 \\
\hline 3 & 12.5 & $9.5 \sim 12.0$ & $9.5 \sim 12.5$ & \\
\hline
\end{tabular}

Table 2. RSSI and maximum range

\section{VERIFICATION EXPERIMENT BY SENSOR}

A chapter 4 shows that only use of an active RFID could not possible to obtain the accurate position information.

Therefore we consider obtaining more accurate position information by using both of active RFID and passive sensors. The sensors receive the signal from objects within $1.5 \sim 3 \mathrm{~m}$ radius. Further high accuracy of indoor position information can obtain by a combination of active RFID and passive sensor is to utilize the advantage of both sensors.

Then seamless positioning from indoor to outdoor will be able to do accurately by a collaboration of geoinfomatics technology.

\section{$5.1 \quad$ Equipment}

Equipment was made by TAKENAKA ENGINEERING Co., Ltd.

Passive sensor: PA-6705

Power-supply device: switching AC adapter (9V)

Electrical cable: AWG22 $\left(0.3 \mathrm{~mm}^{2}\right)$

The feature of sensor is to detect human and object with heat by infrared ray. It is connected to RFID reader and transmits signal to reader.

\subsection{Experimental method}

Confirmatory experiment was conducted whether a passive sensor detected examinee on any position in a room. An examinee entered detecting area of sensor from $\mathrm{X}$ and $\mathrm{Y}$ direction as shown in Figure 7 , and he or she repeated 100 times this action for each direction. $\mathrm{X}$ direction shows front side of sensor. Examinee's walking speed is 3 levels which was normal walk, brisk walk and run. We assumed speeds which person generally walks inside a room.

\subsection{Results and considerations}

Table 3 shows average and standard deviation of detecting position that examinee entered detecting area of sensor for each direction. As a result, all detected position of sensor was within a $1 \mathrm{~m}$ radius, regardless of walk speed. Thus, combination of active RFID and passive sensor is better than that of single use.

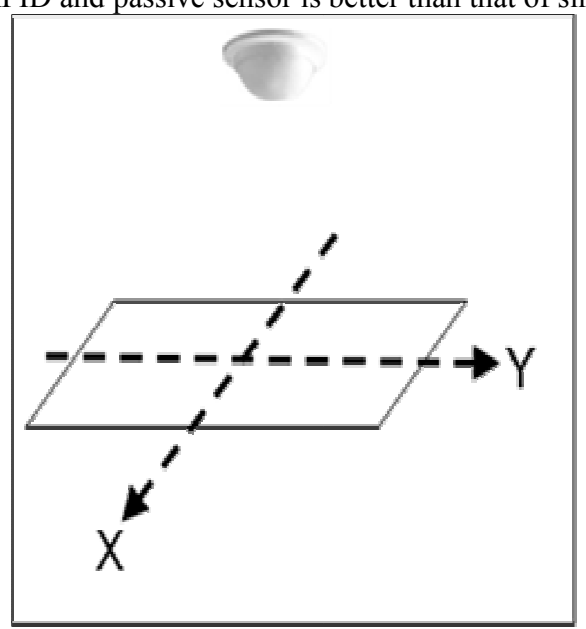

Figure 7. Experimental outline of RSSI and ATT

\begin{tabular}{|c|c|r|r|}
\hline & & \multicolumn{1}{|c|}{ average } & standard deviation \\
\hline \multirow{2}{*}{$\begin{array}{c}\text { normal } \\
\text { walk }\end{array}$} & $\mathrm{X}$ & 13.24 & 8.8960 \\
\cline { 2 - 4 } & $\mathrm{Y}$ & 62.89 & 13.1775 \\
\hline \multirow{2}{*}{$\begin{array}{c}\text { brisk } \\
\text { walk }\end{array}$} & $\mathrm{X}$ & 30.23 & 10.7477 \\
\cline { 2 - 4 } & $\mathrm{Y}$ & 99.78 & 9.5787 \\
\hline \multirow{2}{*}{ run } & $\mathrm{X}$ & 5.68 & 6.4107 \\
\cline { 2 - 4 } & $\mathrm{Y}$ & 63.02 & 15.7601 \\
\hline
\end{tabular}

Unit: $[\mathrm{cm}]$

Table 3. Detecting position from $\mathrm{X}$ and $\mathrm{Y}$ direction

Researcher who applies tag and RFID to people can obtain accuracy position by using the idea.

Active RFID is more expensive than passive sensor. We suggest that to get indoor position at good condition is as follows: Use the wireless LAN if you want to detect the person on the floor. Use the Active RFID if you want to detect the person in the room. Use a combination of Active RFID and passive sensor if you want to detect further detailed position of person in the room. User is possible to reduce the costs of the system by depending on the using purpose.

\section{DEMONSTRATION EXPERIMENTS OF QZSS}

\subsection{JAPANESE GEODETIC SATELIE}

We will conduct experiment for realizing an advanced spatial information society in the future. As described a chapter 3, QZSS was launched in 2010 by JAXA and is satellite system taken by a combination of multi orbit plane and each satellite deployed to appear constantly 1 satellite near the zenith in Japan. Japan and other neighboring countries will be able to receive signals from QZSS anytime and anywhere when 3 satellites of QZSS will be launched. However, QZS launched only one satellite and signal received area from a satellite is limited. Therefore, it is using for the purpose of demonstration experiment in Japan since launch. KIT(Kanazawa Institute of Technology) are joining this experiment and be doing the demonstration experiment of a part of Hokuriku area in Japan. If the experiment is successful, positions will obtain at an area surrounded by canopies and buildings without affecting by cycle slip and multi-path.

In the chapter 6 we describe in detail which demonstrated experiments results March and April in 2012. 


\section{2}

\section{SPAC Demonstrated Experiment in Japan}

SPAC(Satellite Positioning Research and Application Center) activities according to description of the homepage are expand the utilization of geospatial information within industrial and economic sectors including linkage with companies and associations related to satellite positioning, the promotion of research and study related to the use of next-generation satellite positioning, such as the United State's GPS, Europe's Galileo project and Japan's Quasi-Zenith Satellite System, as well as diffusing the results of such activities, and contributing to the activation and commercialization of business activities related to geospatial information. Especially, Quasi-Zenith Satellite System(QZSS) called "MICHIBIKI" launched in 9th September 2010 by JAXA has been demonstrating by many companies and universities. KIT and many surveying companies in Hokuriku District participated SPAC demonstration experiments since early 2010.

QZSS has 2 types signal. One is similar to GPS and another is original signal of QZSS. QZSS has two kinds of original signals, one is L1-SAIF called sub-meter signal and another is LEX signal called centimeters signal. Our laboratory received LEX signal which is able to use corrected information using an electronic reference station in Japan.

Figure 8 is LEX signal receiving apparatus on the automobile for move experiments.

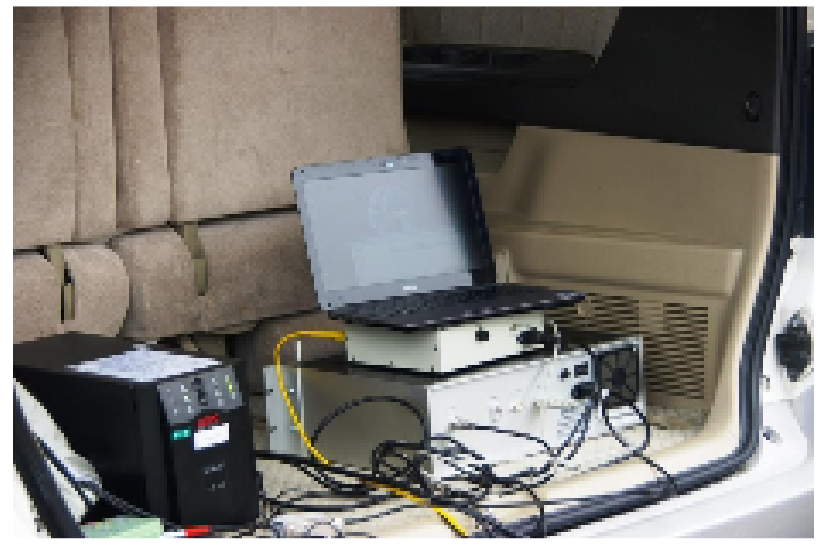

Figure 8. LEX signal receiving apparatus

\subsection{Demonstrated Experiments Results}

\subsubsection{Moving Observation}

Figure 9 shows a photograph under experiment using LEX signal receiving apparatus on the automobile with GPS receiver, right side antenna is receiving GPS signal and left side antenna is receiving LEX signal. On the experiments, received signal was GPS satellite only. QZSS has similar signal of GPS , however, the experiment receiving apparatus did not have the system to receive QZSS's GPS signal.

Automobile ran in the campus, Kanazawa City, Nonoichi City and Hokuriku highway, the velocity of the car was 30 $\mathrm{km} / \mathrm{h}$ to $60 \mathrm{~km} / \mathrm{h}$ in the city, and it was $80 \mathrm{~km} / \mathrm{h}$ to $100 \mathrm{~km} / \mathrm{h}$ on the highway. Run course of automobile has variety area which is tunnels, mountain area, flat area, city area and local area. Figure 9 shows automobile went into a tunnel and Figure10 shows locus of a car in the experimental areas including highway. Background map is fundamental spatial data of Geospatial Information Authority of Japan(GSI) and accuracy of fundamental spatial data is $1 / 2500$.

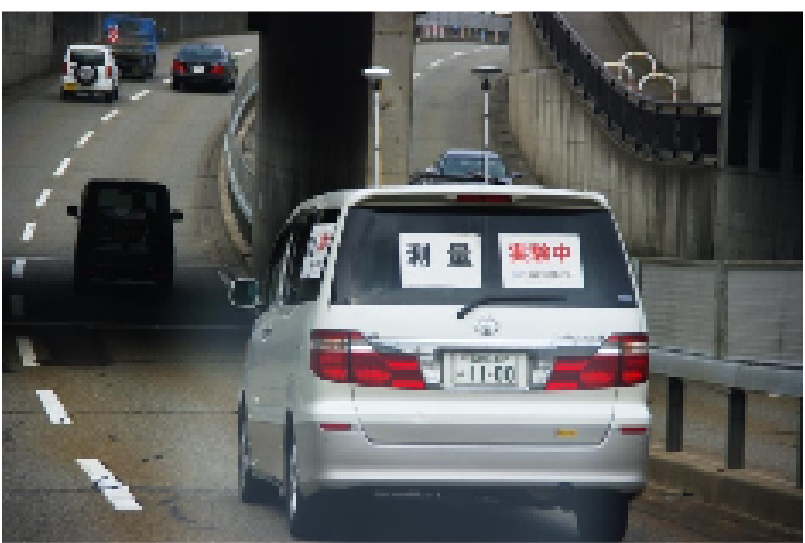

Figure 9. Moving observation

Symbol of a green dot shows GPS and LEX signal at every seconds, and red symbol is shown that was not able to receive a LEX signal. LEX signal is $5 \mathrm{~Hz}$ (five data in every seconds). GPS signal has been received through almost all courses, however, LEX signal was not able to be received in some places. Especially, over $80 \mathrm{~km} / \mathrm{h}$ run on the highway, LEX was not able to receive(Graph in Figure 10). Other researcher in the Japan reported that more than $30 \mathrm{~km} / \mathrm{h}$ LEX signal not received however, our experiments on the highway can receive at $80 \mathrm{~km} / \mathrm{h}$ some places. It is new knowledge of MICHIBIKI LEX signal's activity.

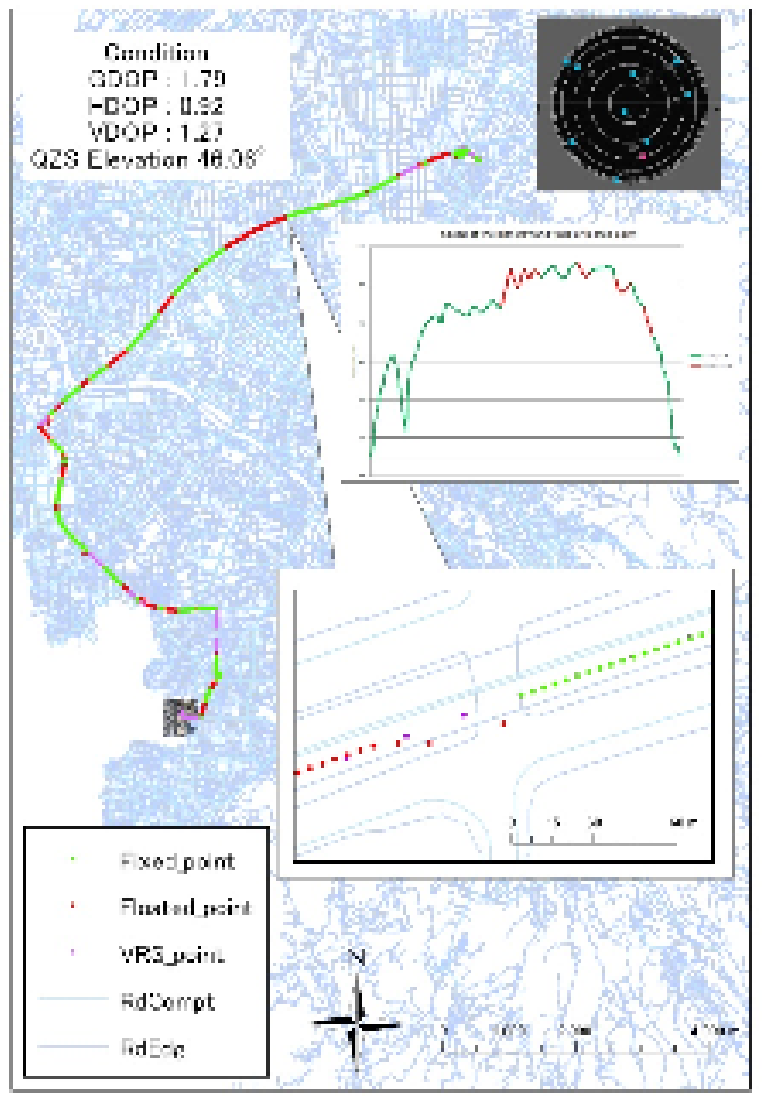

Figure 10. Observation result on the fundamental geospatial data

\subsubsection{Fixed-Point Observation}

Figure 11 shows the condition of fixed-point observation of LEX signal. The fixed-point used the triangulation station in the Naoe area of Higashi of Kanazawa. Purpose of the 
experiment is to confirm reduction of survey time and influence of multipath near the building and Figure11 shows the relationship between surveying time and accuracy. Investigation of the time interval was changed from 30 seconds to 300 seconds, for example, $1-30$ s and $2-30$ s in Figure 11 shows 30 second surveying of 1 st experiment data and 2 nd experiment data respectively .

As the results, almost all same value was shown even if observed time was short, it turned out that an exact value is shown.

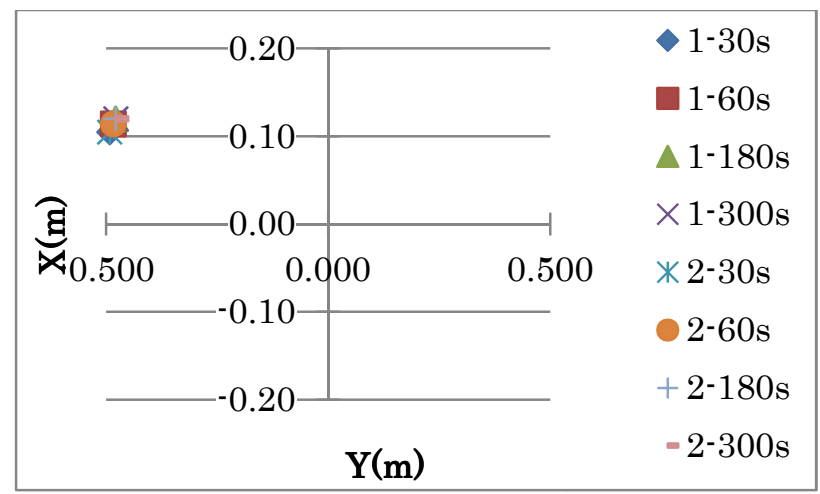

Figure 11. Observation results of LEX signal (Fixed Point)

Fixed-position experiments for LEX signal of QZSS(MICHIBIKI) was success. However we have to conduct detail analysis of an experimental result after this. After submitting this paper, the 2nd demonstrated experiment will carry out. In an experiment, the place which cannot receive a LEX signal is due to attach a camera to a car and to be pinpointed. Detail of analysis will show at the conference presentation.

\section{CONCLUSION}

Establishment of NSDI gave us to chance to promote of advanced geospatial information society, and an experiment was conducted by using passive and active RFID. Chapter 3 shows seamless positioning was conducted by GPS and passive RFID. As a result, it is possible to do indoor positioning by setting passive RFID. Thus, combination of GPS and passive RFID is useful tool for seamless positioning. However, the part where tracks of the GPS overlapped with tracks of the RFID existed. The number of tag should be decrease to use this principle in a social experiment. Therefore, it was necessary to investigate method to minimize the track of GPS and RFID overlapping to minimize time and labor. The solution of the problem is to use QZSS. It is expected to obtain high accuracy position information around the building, and the problem may solve by QZSS. Then seamless positioning from indoor to outdoor will be able to do accurately by a collaboration of geoinfomatics technology.

A chapter 4 shows experiment was conducted by Active RFID to obtain indoor position. As a result, it cannot obtain the exact location by using active RFID only. Therefore we consider obtaining more accurate position information by using both of active RFID and passive sensors. Verification experiment was performed whether a passive sensor detected examinee on any position in a room. As an analysis, sensor's detection area was within a $1 \mathrm{~m}$ radius regardless of walk speed. Thus, combination of active RFID and passive sensor is better than that of single use. It is possible to obtain high accuracy indoor position, and it will reduce the cost of the system using the method suggested by us.
A chapter 5 described first demonstrated experiments of QZSS(MICHIBIKI) at the Hokuriku area in the Japan and two experiments showed the useful experimental result. The LEX signal has been received at least not less than $80 \mathrm{~km} / \mathrm{h}$ and even if observed time was short, it was able to take exact data . We are going to continue the experiment of QZSS(MICHIBIKI) in the future.

We hope to achieve advanced spatial information society which can easily obtain indoor and outdoor position anytime and anywhere using GNSS and RFID as shown in the Figure 12 in near future.

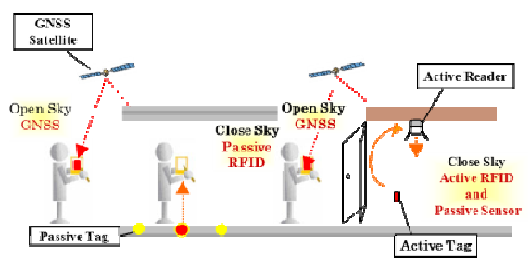

Figure 12. Concept of Seamless positioning experiment

\section{REFERENCES}

Masaaki, S., 2009. APPLICATION OF REAL TIME GIS, REMOTE SENSING AND IC TAG FOR REALIZATION OF GEOSPATIAL INFORMATION SOCIETY, Geoscience and Remote Sensing, In-tech, pp. 153-180.

Fernando. S., 2010. Improving RFID-Based Indoor Position Accuracy Using Gaussian Processes. Indoor Position and Indoor Navigation, Zürich, Switzerland.

Mitoshi, M., 2008. Map renewal technique for Local Government by using REAL TIME GIS, GPS and Remote Sensing. In: The International Archives of the Photogrammetry, Remote Sensing and Spatial Information Sciences, Beijing, China, Vol. XXXVII. Part B4, pp.893-898.

Sota, S., 2008. AVAILABILITY OF REAL TIME GIS AND IC TAG FORREALIZATION OF UNIVERSAL MAP. In: The International Archives of the Photogrammetry, Remote Sensing and Spatial Information Sciences, Beijing, China, Vol. XXXVII. Part B4, pp.899-904.

Tatsuo, A., 2007. Universal Map for Spatial Information Society by Using REAL TIME GIS, GPS and Remote Sensing. In: International Geoscience and Remote Sensing Symposium, Barcelona, Spain, pp.2192-2194.

S. Takeuchi and M.Shikada,APPROACH OF THE INDOOR AND OUTDOOR SEAMLESS POSITIONING BY USING RFID AND GNSS; Mobile Mapping Technology MMT2011;Proceedings,(CD-ROM);2011

\section{ACKNOWLEDGEMENTS}

The authors wish to special thanks to Mr.Manabu Tsuchiya, Mr.Naoki Shirai and Mr.Sota Shimano of KOKUSAI KOUGYO Co., LTD., which offered much suggestion. Moreover, we would like to express our heartfelt gratitude to the cooperation of Mr.Kensuke Taira of KYUSYU TEN Co., Ltd., which supplied active RFID and information. Finally, we would like to express special thanks to Mr. Matsuoka of SPAC who supported the QZSS experiment of Hokokuku area. 